\title{
Differences in use without deficiencies in competence: passives in the Turkish and German of Turkish heritage speakers in Germany
}

Article

Accepted Version

Bayram, F., Rothman, J., Iverson, M., Miller, D., Puig Mayenco, E., Kupisch, T. and Westergaard, M. (2019) Differences in use without deficiencies in competence: passives in the Turkish and German of Turkish heritage speakers in Germany. International Journal of Bilingual Education and Bilingualism, 22 (8). pp. 919-939. ISSN 1747-7522 doi:

https://doi.org/10.1080/13670050.2017.1324403 Available at https://centaur.reading.ac.uk/69576/

It is advisable to refer to the publisher's version if you intend to cite from the work. See Guidance on citing.

To link to this article DOI: http://dx.doi.org/10.1080/13670050.2017.1324403

Publisher: Taylor \& Francis

All outputs in CentAUR are protected by Intellectual Property Rights law, including copyright law. Copyright and IPR is retained by the creators or other copyright holders. Terms and conditions for use of this material are defined in the End User Agreement. 


\section{www.reading.ac.uk/centaur}

\section{CentAUR}

Central Archive at the University of Reading

Reading's research outputs online 
Differences in Use without Deficiencies in Competence: Passives in the Turkish and German of Turkish Heritage Speakers in Germany

Fatih Bayram $^{1,2}$, Jason Rothman ${ }^{2,3}$, Michael Iverson ${ }^{4}$, Dave Miller $^{2}$, Eloi Puig-Mayenco², Tanja Kupisch $^{3,5}$ and Marit Westergaard ${ }^{3,6}$

Ordu Universitesi ${ }^{1}$, University of Reading ${ }^{2}$, UiT the Arctic University of Norway ${ }^{3}$

Indiana University ${ }^{4}$, Universität Konstanz ${ }^{5}$, NTNU, Norwegian University of Science and Technology 6

\section{Corresponding Author}

Jason Rothman (j.rothman@reading.ac.uk)

*The first author was funded by the Scientific and Technological Research Council of Turkey, (Project REF:

B.14.2. TBT.0.06.01-21514107-020-155999) during the writing of this paper. We would like to thank Nadine Kolb and Denny Berndt for help in collecting the German native control data in Berlin and Nuh Doğan, Ferhat Baytürk and Nesli Yılmaz for helping us collect data from Turkish controls in Ordu. Any and all remaining errors are inadvertent and are the responsibility of the authors. 


\begin{abstract}
Determining how and why adult outcomes of heritage speaker (HS) bilingualism differ from monolinguals is difficult because it requires the reconstruction of developmental paths from end-state data. In an effort to address this issue, we examine HSs of Turkish in Germany at an early age of development (10-15 years old, $n=22)$, as well as age-matched monolingual controls in Turkey $(n=20)$ and Germany $(\mathrm{n}=20)$, using a structured elicitation task for production of passives. The goal is to see whether HSs have the representation of passives in their mental grammars and to better understand the relative weight of factors (age at time of testing, immigration status of the Turkish parents (first or second generation), and literacy in the L1) that potentially contribute to the formation of HSs' grammatical competence. The results show that all HSs have the underlying representation for passives in both Turkish and German. There was a significant effect of only literacy; high level of L1 literacy has a positive effect on monolingual-like production as compared to those with no literacy. We discuss these results pertaining to explicating ultimate attainment outcomes in heritage language acquisition in relation to larger debates in the field.
\end{abstract}

Key words: Heritage Speaker Bilingualism, Passives, Turkish, German, Production, Literacy 


\section{Introduction}

Although it is not always the case that heritage speaker (HS) bilinguals differ from monolinguals of comparative ages (see, e.g., Kupisch and Rothman 2016), HS deviation from monolingual performances on experimental tasks - potentially representing bona fide differences in mental grammars- is not uncommon (see, e.g., Montrul 2008, 2016). It is important to define what we mean by HSs from the beginning. HSs, like any other bilinguals, have grammatical and communicative competence in more than one language; however, it is the specificity of the sociolinguistic conditions under which HSs acquire competence in both of their languages (the home and societal majority one) that qualifies one as a HS. We follow Rothman's (2009) definition of what a heritage language (HL) is and how, in principle, it is acquired because it sidesteps the labelling of HS competence differences as deficits of any kind and leaves open the relative weight of a series of contributory factors that likely interact to explain HS outcomes. According to this definition:

[a] language qualifies as a heritage language if it is a language spoken at home or otherwise readily available to young children, and crucially this language is not a dominant language of the larger (national) society [...] the heritage language is acquired on the basis of an interaction with naturalistic input and whatever in-born linguistic mechanisms are at play in any instance of child language acquisition. Differently [from monolingual acquisition], there is the possibility that quantitative and qualitative differences in heritage language input, influence of the societal majority language and differences in literacy and formal education can result in what on the surface seems to be arrested development of the heritage language or attrition in adult bilingual knowledge (Rothman 2009, 156).

Thus, a HS is a bilingual individual whose native first language is a minority language in a majority language context; that is, where the language of the home environment and potentially a subset community differs from what is spoken in the society as the majority language. For example, a child born to Turkish immigrant parents in Munich or a child born to German immigrant parents in Istanbul will grow up to be a HS of Turkish and German respectively. As stated above, HSs typically 
differ in linguistic performance (from spontaneous production to performances across experiments) as compared to age-matched monolinguals. They are typically dominant in adulthood in the majority language of the society, despite its (most often) being chronologically a second language (L2) acquired in early childhood. The starting point in the shift of dominance from home language to the majority language often corresponds to the onset of formal education in the majority language.

For well over a decade, it was essentially assumed that HS differences must reflect incomplete acquisition or attrition, the former being the arrested development of HS grammar in early childhood and the latter being the loss of previously acquired competence, in both cases due to a shift in dominance towards the majority language over time (Montrul 2008). More recent work has challenged this assumption (e.g., Kupisch 2013; Kupisch and Rothman 2016; Pascual y Cabo 2013; Pascual y Cabo and Rothman 2012; Pires and Rothman 2009; Putnam and Sánchez 2013; Rothman 2007; Scontras, Fuchs and Polinsky 2015). These newer approaches argue that differential ultimate attainment in the HL is not a case of incomplete acquisition, but rather reflects alternative developmental paths that arise because of the variation HSs confront related to key factors that contribute to monolingual conformity. The claim is that one should not view differences as incomplete per se, precisely because such outcomes are expected due to quantitative and qualitative differences in variables such as input, formal literacy in the HL, cross-linguistic influence (CLI), and issues related to processing (e.g. issues that arise due to simultaneous activation of both systems) Rothman 2009).

None of the above approaches (i.e., incomplete acquisition, attrition, alternative developmental paths) to explaining HS differences are mutually exclusive; that is, all potentially contribute insights into explaining the full gamut of variation that characterizes HS competence. Nevertheless, we seek to have an accurate account for how and why discrete domains of HS grammars present the way they do, for which we will need to differentiate between incomplete acquisition and alternative developmental paths as we test HSs domain by domain. There are at least two ways to test 
the applicability of these explanations against one another. First, one could consider more exhaustively other predicted consequences of what is claimed by any given approach and see if doing so in consideration of larger sets of data presents more support for one approach over the others. For example, under a scenario where a grammatical representation has not been fully acquired (incomplete acquisition) and/or truly attrited, one would expect converging evidences to point in the direction of differences in underlying grammatical representations. Imagine that HSs of Russian or Spanish growing up in the USA were to have incompletely acquired or attrited the system of grammatical gender. One would not only expect them to have difficulties in producing agreement between a head noun and an adjective. They might, for example, be less sensitive or insensitive to secondary comprehension effects of gender (e.g., nominal ellipsis (n-drop) licensed by gender, see White et al. 2004) and/or exhibit reduced sensitivity to grammatical cues/violations when processing gender (e.g., reduced markedness effects between default and non-default gender, see Alemán Bañón and Rothman 2016; Alemán Bañón, Miller and Rothman, in press). If, however, HSs only show differences in the production of gender agreement, and especially do so with particular empirical measures (offline, but less so online), then concluding that a representation is incomplete or attrited is premature. HSs might simply have a problem with gender assignment at the lexical level, for example, potentially due to reduced input, but not a problem with the syntactic operation of agreement per se (see Hopp 2013 for adult L2 acquisition; Kupisch, Akpınar and Stöhr 2013, Irrizari van Suchtelen, 2016 for HSs). The divergence from monolinguals would still qualify as a HS difference; it is simply not clear that such a difference would relate to an incomplete representation in the mental grammar of HSs via arrested development or attrition.

Secondly, one could examine predicted differences in HL developmental sequencing to monolinguals in early childhood (real time development in younger HSs) or forgo the monolingual comparison altogether, contrasting the anticipated differences between HSs at various ages (apparent time comparisons between child and adult HSs, which under an attrition account should be different). 
Although the vast majority of HS studies have examined the competence of endstate HL grammars, they have almost always used these data to make claims about the developmental path itself. It is not clear, however, how to adjudicate between competing proposals for the outcome differences from endstate data. For example, incomplete acquisition versus attrition versus input delimited differences might be, in principle, equally likely to best explain "how" HS adult grammars arrived at a given competence for property $\mathrm{X}$ under inquiry from the vantage point of knowing the outcome. That is, they might be equally probable to explain "how" an observable outcome obtained, but as usual, the devil is in the details. Since all proposals predict HS differences from monolingual baselines, the real question is not which proposal fares the best descriptively, but rather, which also offers the best explanation. In other words, how well does each address the "why"? It is not enough to describe differences as such, but one seeks to know why differences obtain the way they do and, of equal importance, what mental representations in HSs actually look like as a result.

In an attempt to avoid reconstructing a developmental path from endstate data alone, a few recent studies have employed interesting comparative designs (e.g. Barton 2015; Kupisch, Lein, Barton, Schröder, Stangen and Stoehr, 2014; Montrul and Sánchez Walker 2013; Pascual y Cabo 2013; Pires and Rothman 2009; Polinsky 2011; Rothman 2007). Rothman (2007), Pires and Rothman (2009) and Montrul and Sánchez Walker (2013) each investigate the role that qualitative differences in the input to which HS versus monolingual children are exposed (e.g., as a consequence of grammatical change/L1 attrition effects in the input) might better explain the path and ultimate attainment of particular grammatical properties. Kupisch and colleagues (see Kupisch and Rothman, 2016, for a review of studies) have compared HSs who have had the HS as a medium of instruction at school to those who have not. This work convincingly shows that HS differences effectively disappear when input qualities and quantities are comparable. They argue, by extension, that divergences in HS competence from the monolingual baseline might obtain as a result of inaccessibility to formal education in the HL, which fills in the qualitative input gap and significantly 
lessens the impact of the quantitative one. Finally, Polinsky (2011) and Pascual y Cabo (2013) have tested young HSs (before 10) and compared them to other groups, including adult HSs, monolingual children and adult monolingual controls. Such a comparison can show whether they develop monolingual-like to a particular level at a specific age and, if they do, the extent to which they retain this or attrite into adulthood.

In the absence of truly longitudinal studies, the above methodologically innovative approaches embody a significant step in the right direction. However, documenting a crucial timeframe is missing in the HS literature. As independently pointed out by Allberse and Hulk (2016) as well as Kupisch and Rothman (2016), we need to know what happens to HSs developmentally between the ages of young childhood (ages 2-9) and early adulthood (age 18 onwards). The polar ends of the continuum are well represented; we know much about HS children from the fields of child simultaneous bilingualism and child L2 acquisition (since HS children are one or the other) and about adult HS grammatical outcomes as described by the overwhelming majority of studies for the past two decades. Since many child bilingual studies have provided evidence in favour of monolinguallike acquisition paths (see De Houwer 1995; Haznedar 2013; Meisel 2004 but Meisel 2011 for an overview of 2L1 acquisition) despite some developmental delays, and adult HS studies most typically show significant endstate differences (see Benmamoun, Montrul and Polinsky 2013; Montrul 2016), Kupisch and Rothman (2016) are well positioned to argue that an important focus for HS studies moving forward must include the determination of exactly what is happening between late childhood and early adulthood. This age group is of crucial importance since this undetailed timeframe of HL development is precisely when exposure to both languages under a variety of conditions determines the extent to which HSs will become (im)balanced as regards their competence in the languages they speak as adults. In an effort to provide data from such a rarely documented age group of HSs and thus begin to address how such data might inform competing proposals for HS differences, we present a 
study examining the production of passives in the German and the Turkish of HS Turkish-German bilinguals growing up in Germany between 10 and 16 years of age.

One goal of the present research is to better understand the relative weight of factors contributing to the formation of HSs' grammatical competence and ensuing use of the HL within the age range where dominance in the majority language solidifies. We do so by addressing the issue of descriptive adequacy for HL ultimate attainment (i.e., whether it is incomplete, attrited or has completely developed on an alternative path), while simultaneously striving for explanatory adequacy regarding how any such outcome obtains in the HS context, including variables that potentially account for intragroup variation. We investigate HS grammatical competence in relation to environmental/(socio)linguistic factors, juxtaposing their L1 (Turkish) and L2 (German) performance with a number of key variables such as their age at time of testing, immigration status of the Turkish parents (first or second generation), and formal training/literacy in the L1. We examine (morpho)syntactic passives, which have a fairly complex representational structure (syntaxsemantics) and high processing cost in order to see whether or not HSs differ as compared to monolinguals of the same ages already in older childhood. Furthermore, we test the HSs' knowledge in their L1 HL and their dominant L2 and compare this to age-matched monolingual control groups of both languages to determine whether there is any evidence of cross-linguistic effects, and if so, in which direction(s).

\section{Passives in Turkish and German}

Passives are generally a late-acquired property in most languages (e.g. Babyonyshev and Brun, 2003 (Russian); Abbot-Smith and Behrens, 2006 (German); Mills 1985 (German); Borer and Wexler 1987 (English); Chang 1986 (Mandarin); Fox and Grodzinsky 1998 (Spanish, English); Fox, Grodzinsky and Crain 1995 (English); Gabriel, 2001 (Portuguese); Gavarró and Parramon, 2011 (Catalan); Pierce 1992 (Spanish); Terzi and Wexler, 2002 (Greek); Sugisaki 1999 (Japanese)). Many accounts have 
attempted to explain why passives are acquired so late in the majority of languages. Hypotheses include syntactic maturation (Borer and Wexler 1987), claims that children have problems with interpretation/syntax of the by-phrase (Fox and Grodinzsky 1998), some elusive notion of derivational complexity (Brown and Hanlon 1970), and frequency-based accounts highlighting the scarcity of passives in relevant input (Tomasello 2000), the latter supported by claims that English children as young as 3-4 years can be coerced into producing passive constructions through training (Brooks and Tomasello 1999).

For our purposes, the precise reason for the general late child acquisition of passives is irrelevant. It is enough to know that its full acquisition and mastery happens later in German than in Turkish and that there is some general complexity inherent to passives, both of which we expand upon below. However, it is relevant to point out that late acquisition of the passive is not entirely universal. This tells us that none of the above reasons offered in the literature for late acquisition of passives can be the whole story, since the same issues pertain to all languages. In some languages (crucially including Turkish), children seem to converge quite early (2 years of age), and there seems to be some correlation with language type and morphology. That is, children of Bantu, Turkic and Inuit languages, such as Sesotho, Kiswahili, Turkish, Inuktitut, have been shown to have full knowledge of passives quite early (Alcock, Rimba and Newton 2013; Allen and Crago 1996; AksuKoç and Slobin 1985; Demuth and Kline 2006; Ketrez 1999; Savaşır and Glee 1982;). Moreover, it seems that in these languages passives might be used more as well by adults (Demuth and Kline 2006). These languages are all agglutinative, indicating that there is something about agglutination itself that circumvents later acquisition of this property, perhaps the existence of a dedicated and obligatory morpheme for passives. For example, as a language with rich agglutinative morphology, Turkish exhibits highly consistent and clear grammatical regularity for the relationship between the surface forms of verbal morphology and the case marking system (Slobin 1986). The transparent mappings in Turkish arguably facilitate the learning of grammatical (nominal and verbal) morphology 
at early ages, mostly before the age of 2 (Aksu-Koç and Slobin 1985; Batman-Ratyosyan 2004; Topbaş et al. 1997; van der Heijden 1999; Xanthos et al. 2011). Analyses of speech production of Turkish monolingual children report that passive morphology emerges as early as age 1;6 and is progressively used productively with full mastery of all passive structures around the age of 3 (AksuKoç and Slobin 1985; Ketrez 1999; Savaşır and Glee 1982). As for German, passive constructions are known to be rare until the age of 4 (Mills 1985), although there is some indication that they appear somewhat earlier than in English. Based on a high-density longitudinal corpus, Abbot-Smith and Behrens (2006) report that the monolingual child Leo used sein-passives by age 2;2 and werdenpassives only a few months later, by 2;5. Aschermann, Gülsow and Wendt (2004) compared the comprehension of passives in 106 English- and German-speaking children at the ages between 3;0 and $8 ; 0$, showing that the German children interpreted passives in a target-like manner at around age 5;0, while the English children did so at an age around 6;0. While results are not entirely comparable due to methodology (e.g. spontaneous vs. experimental, production vs. comprehension) and focus (e.g. first use vs. mastery), it seems clear that passives are less frequent and later acquired in German than in Turkish.

In light of the above, passives seem to be a good candidate to test because: (i) they are acquired later in the majority language, (ii) they are fully acquired earlier in the HL (so should be in place before the shift in dominance takes hold), (iii) the morphosyntax of passives is different enough in the two languages, especially morphologically so, that crosslinguistic influence might be less likely, and finally (iv) passives are argued to be cognitively costly in general, thus they should be especially so for bilinguals. Therefore, our HSs should have had the opportunity to acquire the passive in Turkish before any effect from German would have stunted its development and it is likely that this construction will be retained in Turkish over time.

It is perhaps prudent to expand on the claim in (iv). Passives are cognitively more costly than actives given the reanalysis of theta-role mappings they require. The details of both German and 
Turkish are explained in greater detail below. For now, suffice it to say that in active sentences there is an alignment between grammatical (syntax) and thematic role (semantics) assignment - the thematic role of Agent is mapped to the subject and Patient/Theme on the object straightforwardly. In passives, the thematic role mapping is reversed - the Patient is mapped to the structural subject and the Agent to the NP in the by-phrase. Turkish, an agglutinative language, has a dedicated morpheme on the verb that signals the passive and is therefore more transparent in this respect than German.

Ferreira (2003) offers an account of how the non-canonical relationship of grammatical and thematic role assignment affects the processing of passives. She proposes an incremental view of processing with a parser that has a general bias for assigning the thematic role of Agent to the first encountered NP. Consider examples (1) and (2):

(1) Owen hugged Leo.

(2) Leo was hugged by Owen.

In an active structure such as (1), Agent is assigned to Owen and Patient to Leo. However, in passives, as in (2), Leo is first assigned the Agent role, the morphology of 'was' is, up to this point compatible with this assignment, but upon hearing the past participle morphology in 'hugged', the parser knows it is a passive. Thus, the Agent role is no longer possible and a reanalysis is required to assign the Patient role to Leo and eventually the Agent role to the NP in the by-phrase. Other complexities conspire with passive structures to make processing more challenging, such as the ambiguity of the preposition $b y$, which could introduce an agentive interpretation, as in example (2), or a locative interpretation as in 'Leo was hugged by the side of the road'. Given Ferreira's (2003) account, non-canonical sentences are predicted to be more costly to process. This might explain individual differences in processing passives across healthy native speaking adults (e.g., Leech et al. 2007), a general decline in production of passives in older healthy adults (between 65 and 100 years) corresponding to natural cognitive ageing -especially where cognitive ageing is accelerated by 
neurodegeneration, e.g., with Alzheimer's disease (Bates et al. 1995)- and thus why passives are generally less frequent than actives.

\subsection{Passives in Turkish}

The default canonical word order in Turkish is SOV. The Thematic roles of Agent and Patient/Theme are canonically mapped onto syntactic arguments. As seen in (3), the subject is nominative -signaled as such by the obligatory null morphology- and the Object is overtly marked with accusative morphology:

(3) Bir kadınçamaşır-lar-1 as-tı.

a woman-NOM cloth-PLU-ACC hang-PAST-3SG

'A woman hung the clothes.'

Turkish passives involve realignment of argument roles through suppression of the Agent theta role and promotion (movement) of the patient/theme argument (Özsoy 2009). The passive construction requires obligatory adjunction of an allomorph of $[-11]$ on the verbal predicate that itself signals the passive-the phonological context determines which allomorphic variant is required. ${ }^{1}$ The moved theme argument, that is normally marked with accusative, appears with nominative marking in the passive counterpart. In this case, the transitive verb marked with the passive suffix agrees in person and number with the internal argument that is moved to the subject position as in (4).

(4) Çamaşır-lar- $\varnothing \quad$ (bir kadın tarafından) as-ıl-dı-lar. cloth-PLU-NOM (a woman by) hang-PASS-PAST-3PLU. 'The clothes were hung by a woman.'

\footnotetext{
${ }^{1}$ The passive suffix becomes $-(l) l$ after consonants, $-n$ after vowels and $-(l) n$ after laterals. The $(l)$ stands for a vowel, harmonizing to the closest vowel to it in the stem.
} 
As illustrated in (4), the agent in a personal passive construction in Turkish can (optionally) be expressed as the complement of the agentive postposition tarafindan-phrase. Turkish does not distinguish between different types of passives (i.e., stative vs. eventive) in terms of their morphosyntactic structure; that is, both passives are formed by the use of the allomorph of the suffix $[-11]$ on the verbal predicate.

\subsection{Passives in German}

Although German is underlyingly SOV, like Turkish, it shows SVO order in main clauses with verbs in simple tense, as illustrated in (5). This is due to the V2 requirement, moving the finite verb to second position. As in Turkish, theta-role assignment is typically mapped faithfully onto canonical syntactic positions. That is, the NP in the structural subject position of agentive verbs is assigned the Agent theta role, ein Junge 'a boy' in (5), and the NP in the object position, einen Apfel 'an apple' is assigned the patient role. German also overtly marks for Case, which is morphologically realized on items that show agreement dependencies with the noun, for example articles and adjectives. In (5), the definite article der bears nominative case and den accusative case.

(5) Der Junge aß den Apfel.

the.NOM boy ate.PAST the.ACC apple

'The boy ate the apple.'

Passivation in German involves movement of the NP in the underlying object position to the structural subject position — and thus receives nominative case, ein Apfel in (6)—one of two available auxiliaries (sein 'to be' and werden 'to get') is inserted in the V2 position and the past participle appears in verb-final position. If the agent is produced, it appears as a PP in medial position (vonphrase), between the auxiliary and the main verb. 
(6) Der Apfel wurde (von dem Jungen) gegessen.

the.NOM apple get.PAST (by the.DAT boy) eat.PAST-PARTICPLE

'The apple was eaten by the boy.'

German distinguishes stative and eventive passives, which have a similar structure consisting of an auxiliary and a past participle. In both, the focus is on the argument of a transitive action. They differ semantically and morphologically in that the stative passive, illustrated in (11a), takes the auxiliary sein, and denotes the state of the subject that is the result of another entity having acted on it or having affected it. By contrast, the eventive passive, illustrated in (11b), takes the auxiliary werden 'become'. It denotes a dynamic event in which the subject unergoes an action or event caused by another entity. The two are typically referred to as sein-passive vs. werden-passive, respectively. Both can be combined with by-phrase.

a. Die Wand war (von seinem Freund) angestrichen.

the wall be.3rd.sg.PAST by his friend painted.PARTICIPLE 'the wall was in a painted state (havign been painted by his friend)"

b. Die Wand wurde (von seinem Freund) angestrichen.

the wall become.3rd.sg.PAST by his friend painted.PARTICIPLE 'the cake was being painted (by his friend)'

The difference between the two is predomianntly one of tense-aspect distinctions rather than syntactic complexity.

It is important to higlight that the aforementioned distinction between different types of German passives, however, is provided for throughness more than anything else. That is, it is not significant for the purpose of our study. The experimental design itself allows for the use of different types of passives and for our purposes we do not care which they provide as both equally indicate knowledge of the underlying representation and mechanisms of the passive voice. 


\section{Hypotheses and Research Questions}

Recall that while monolingual Turkish children acquire passives fully by 3 years of age (Aksu-Koç and Slobin 1985; Ketrez 1999), monolingual German children do not fully acquire passives until 4-5 years of age (e.g., Abbot-Smith and Behrens 2006; Mills 1985). In the case of Turkish HSs in Germany, then, one might expect arrested development not to pertain to this structure in heritage Turkish. Therefore, we anticipate that HSs will have acquired Turkish passives and that they will retain knowledge of them. Because HSs typically show some differences from controls, we further hypothesize that they may show some differences from Turkish monolinguals in the patterns of using passives in Turkish, but we expect that at least some of this variation will be captured by experiential variables, such as influence from the majority language, literacy in the HL, age at time of testing (i.e. perhaps younger HSs will fair better for having had less time overall to attrite), and factors related to parental background. We expect these HSs to have acquired German passives too, and their distribution as compared to native controls to be monolingual-like, as these HSs are immersed in a German-dominant environment. With all of this in mind, our main research question and two interrelated sub-questions are as follows:

i. Do Turkish HSs in Germany have, at this (young) age of testing, the morphosyntax of passives in both of their languages?

ii. If they can correctly produce the morphosyntactic structure of passives in both languages, does their use of passives nevertheless differ from that of the agematched native controls in one or both of the languages?

iii. If there are differences between the HSs and controls and/or simply between individuals in the HS group, how and why might such differences obtain? 


\section{Methodology}

\subsection{Participants}

The experimental data used in this study come from three different groups of participants; one target and two control groups (see Table 1 below for details).

[Table 1 near here]

The experimental group consists of 22 Turkish HSs in Southern Germany ${ }^{2}$. Apart from two participants $^{3}$ who moved to Germany at the age of 5, they were all born in Germany. Their first intensive contact with German, however, happened when they started going to kindergarten from the age of 3-4. In an oral interview that was conducted in Turkish before the Turkish experiment, all HSs reported German as their dominant language. They also reported having spoken Turkish from birth and still speaking Turkish at home. In addition to using the oral interview as a means to get the HSs into Turkish mode and actively speaking the HL, the information gathered was designed to relate to a number of potential statistical predictors (e.g., literacy in Turkish or if one or both parents were born in Turkey or Germany) to account for individual differences within the HS group. In order to determine their relative level of literacy in Turkish, the HSs were first asked whether they had any formal training in Turkish and whether or not they knew how to read and write in Turkish. For those who answered 'yes', they were then asked to quantify how actively they were engaged in literacy activities in Turkish, that is, how often and under what conditions they read and write in Turkish.

\footnotetext{
${ }^{2}$ Although they spoke the regional Southern variety of German, the use of passive in that variety is not different from its use in Standard German, as described above.

${ }^{3}$ The two HSs who moved to Germany at age 5 started going to school immediately, thus 5 corresponds to their onset of exposure to German.
} 
This was then used to distinguish the 4 levels of literacy we used for our analysis. Each control group had 20 native L1 speakers, consisting of comparable individuals (age, SES, sex), born, raised and tested in their home country, Turkey or Germany, respectively.

\subsection{Test Tool}

Targeting certain linguistic structures may necessitate using "more proactive data elicitation techniques in addition to simply examining spontaneous language production" (Gass and Mackey 2007, 20). As the use of passives requires specific linguistic (pragmatic) context, we designed a communicative task to elicit passives in Turkish and German. The design of the experimental task used in this project was inspired by the original computer-animated fish film by Tomlin (1995 1997).

[Figure 1 near here]

The Fish Film was originally used to test the hypothesis that the syntactic subject in English narratives receives the highest degree of attention than other potential NPs. In the film (see Figure 1), the two fish enter the screen from opposite directions and meet at the center of the screen, at which point one of them eats the other. In each scene, one of the fish (Agent or Patient) receives a visual cue: a flashing arrow to direct the participant's attention to the fish at which the arrow points. In the experiment, the participants were instructed to look at the fish with the cue and freely describe what they observed. The results showed that participants consistently took the fish with the arrow to be the sentential subject. When the arrow was on the Agent fish, participants produced active voice sentences (e.g., 'The blue fish ate the red fish'). When the arrow was on the Patient fish, however, they produced passive voice sentences (e.g., 'The red fish was eaten by the blue fish'). With extremely limited variation, this pattern was true in virtually $100 \%$ of all experimental trials. 
The Fish Film experiment shows that by manipulating the linguistic context through visuals or other cues, speaker's preferences towards using one structure (i.e., passive) over the other (i.e., active) can be influenced too. Similar evidence comes from various priming studies in language production which reveal that speakers who are primed show a significant tendency to re-use lexical and/or structural forms of previous structures provided to them (Bock 1986; Ferreira and Bock 2006; Gass and Mackey 2000; Messenger et al. 2012; Pickering and Ferreira 2008; Rowland et al. 2012). Overall, these studies show that exposure to a stimulus at time 1 influences the response to a related stimulus at time 2 .

In the present study, we created 14 different sets of picture sequences, each of which consisted of 3 or 4 pictures depicting an event, as illustrated in Figure 2 below.

[Figure 2 near here]

We then showed each participant the pictures one by one and asked them to describe what they saw. Instead of the arrow that was used as a visual cue in the Fish Film, questions and the sequencing of events in the pictures were used in the current experiment as linguistic cues. Although participants were not primed in the traditional sense, the way the questions and the sequence of pictures were presented to the participant created a pragmatic shift from the Agent to the non-Agent and made the re-alignment of theta-role mappings natural.

\subsection{Procedure}

The data were collected by native speakers of Turkish and German who did not speak the other language. This was especially necessary for the bilingual group to ensure that they were comfortably established in the target language mode (cf. Grosjean 2010). The HS group was tested in a Hauptschule-a five-year upper elementary school in Germany preparing students for vocational 
schools or the lower levels of public service-in Munich. The order of the testing in Turkish and German was counterbalanced, that is, half of the subjects were tested first in German and the other half in Turkish. Prior to the start of data collection, authorization from the school management and local authorities were secured, who then facilitated the collection of parental consent for each participant.

Each picture was shown to the participant one by one. When presented with the first picture in the sequence (or the first two pictures when there were four pictures in the set), the participant was asked to freely describe what $\mathrm{s}$ /he saw in the picture. Sets of three and four pictures were used on purpose and in a random order such that the subject would be less likely to pick up on the pattern of prompting for the passive structure by focusing on the agent. Regardless of whether the prompting of a passive started in the second picture (for three picture sets) or the third (for four picture sets), the last two pictures always asked a question that focused on the patient (i.e., other pictures asked a nonpatient focused question). In a sense, this was akin to the cue of a flashing arrow in the Fish Film. Since there were 14 picture sets, each with 3 or 4 pictures, and of each picture set only two pictures corresponding to a patient-focused question, the total number of opportunities to produce passives was 28 (fillers then equate to the non-patient focused question for either one or two pictures in each set). An example interaction in English is provided for a set of 4 pictures (cf. the first set of pictures in Figure 2 above):

1 Researcher: What do you see in the first picture?

2 Participant: There is a small fish and a big fish.

3 Researcher: What is happening in the second picture?

4 Participant: The big fish sees the small fish.

5 Researcher: What is happening to the small fish in the third picture?

6 Participant: The small fish is being chased by the big fish. 
7 Researcher: What is happening to the small fish in the fourth picture?

\section{Participant: The small fish is being eaten by the big fish.}

As seen in the sample dialogue above, the questions asked in lines 5 and 7 shift the pragmatic perspective of the discourse from the big fish (Agent) to the small fish (Patient), encouraging the speaker to focus on the Patient rather than the Agent. However, this is not to say that the only acceptable answer to those questions is one in which the passive structure is used. Although the patient/theme-focused questions should create a discourse context in which the passive becomes quite natural, answering with an active sentence is perfectly acceptable as well. Therefore, we do not expect all subjects, monolinguals or HSs alike, to uniquely produce passives. We do expect, however, that each group—-provided they have the underlying representations for passives—will produce passives at least some of the time and, ideally, there will be some consistencies in terms of usage patterns within groups and potentially across some key group comparisons.

\section{Results}

As explained above, even as an answer to a question that focuses on the patient, the passive is not the only licit structure in the given context. The context merely licenses the passive, thus making its use more likely. Although the data to be presented are strictly productions, the structured nature of the experiment facilitates direct comparisons across the HSs in each language compared against controls which will reveal if (and potentially why if not) there are differences in competence and/or use.

The number of passive uses reported below for any individual reflects grammatical productions according to either the Turkish or German grammars. For example, a response counted as containing a passive in Turkish had the [-ll] morpheme (passive morphology) on the verb and reflected the realignment of patient/theme. We had decided to only factor in clear cases of passives to ensure that the analysis does not overestimate use on the part of any given group. Doing so turned out to be rather easy because there in fact were no "ambiguous" productions by any group, i.e., all 
passives produced, by the controls or the HSs alike, were completely grammatical and contextually appropriate in both languages. When an alternative structure was used, it was clearly not a passive, always grammatical in the target language and semantically appropriate in the context of the picture. To make this point more clearly, let's examine some representative answers provided by both the HSs and the controls to the question "What is happening to the small fish" in Turkish, corresponding to the third picture from the first row of picture sets in Figure 2 above. As can be seen in the example, answers provided in $(10)^{4}$ below, either a passive was unambiguously used and thus counted as such or an equally grammatical active sentence was used and thus not counted as a passive use. We offer a few examples of non-passive responses since these varied across individuals whereas provided passives showed very little variation, for example, the verb 'eat' was always used for this picture.

9) Turkish question:

Buradaküçük balığ-a ne ol-uyor/ol-du?

here small fish-DAT what happen-PROG-3SG/happen-PAST-3SG

'What is happening/happened to the small fish here?'

Passive by HSs:

(a) $\mathrm{O}$ ye-n-iyor.

it eat-PASS-PROG-3SG

'It is being eaten.' (HS 19)

Non-passive by HSs:

(b) Şimdi küçük balık kaç-mak isti-yor.

now small fish escape-INF want-PROG-3SG

'Now the small fish wants to escape.'

(HS22)

\footnotetext{
${ }^{4}$ The number reported in parentheses, for example, HS19, refers to the subject (heritage speaker participant number 19 in our coded system) who made the production reported as an example.
} 
(c) Öl-dü.

die-PAST-3SG

'It died.'

(HS5)

(d) Şimdi büyük balık küçük balığ-1 1sır-mak isti-yor.

now big fish small fish-ACC bite-INF want-PROG-3SG

'Now the big fish wants to bite the small fish.'

(HS15)

Passive by Turkish controls:

(e) Ye-n-di.

eat-PASS-PAST-3SG

'It was eaten'

Non-passive by Turkish controls:

(f) Küçük balık mavi balığ-a yem ol-du.

small fish blue fish-DAT food become-PAST-3SG

'The small fish became food for the blue fish.'

(g) Sarı balı̆g-1 ye-di.

yellow fish-ACC eat-PAST-3SG

'It ate the yellow fish.'

(h) Küçük balık büyük balığ-1n ağız-1-na gir-mek üzere.

small fish big fish-GEN mouth-POSS-DAT enter-INF about

'The small fish is about to enter the big fish's mouth.'

Table 2 and Figure 3 presents the data in both Turkish and German across all three groups; Figure 3 presents this visually. The German monolingual group and the HS group (in both languages) produced passives in around $25 \%$ of their responses, while the Turkish monolingual group produced passives considerably more, about $68 \%$. 
[Table 2 near here]

[Figure 3 near here]

The data were analyzed in SPSS using a logistic mixed model. For comparisons between groups/languages, a model was run containing fixed variables of Group (Turkish, German, or HS) and Language (Turkish or German), random intercepts and slopes for subjects, and random intercepts for items. Pre-planned contrasts corrected with Bonferroni adjustment (for 4 comparisons) showed that the Turkish monolingual group was nearly nine times more likely to produce a passive than both the German monolingual group $(p<.001$, odds ratio $=8.91)$ and the HS group in Turkish $(p<.001$, odds ratio $=9.10$ ). The HS group did not significantly differ from the German monolingual group in German $(p>.999$, odds ratio $=1.09)$, nor did the HS group differ from themselves across languages $(p>.999$, odds ratio $=1.07)$

Consistent with the appearance of the descriptive data, the Turkish monolinguals reliably produced more passives than the age-matched German monolinguals. While the HS group produces passives in both of their languages, the rate is similar to that of the monolingual German group. This is not surprising given the typical shift of dominance from home language to societal language in HL environments. As a result, HSs generally wind up being more monolingual/target-like in the societal language than they are in their home language as they grow older. However, variability is one of the hallmarks of HL competence. In Turkish, although the HS group produces significantly fewer passives than Turkish monolinguals in general, thirteen individual HSs produce passives at a rate within the monolingual range (i.e., $\min =7, \max =28$ ).

The question that arises from this picture is what variables might account for these individual differences within the HS group. In order to answer this question, an additional logistic mixed model was run to assess the use of passives in Turkish by HSs of Turkish given age, parental background 
and level of literacy, and all possible interactions. In this model, the following variables were included:

(i) age, referring to the age of the participant at the time of testing (10-16 years old),

(ii) parental background, referring to where the participant's Turkish-speaking parents were born: both in Germany (both second generation), one in Turkey/one in Germany (one first, one second generation), or both in Turkey (two first generation)),

(iii) level of literacy, referring to whether the participant had any formal training in Turkish or not (four levels: no literacy/cannot read or write in Turkish, low level of literacy/very little use of reading or writing in Turkish, medium level of literacy/sporadic use of reading or writing, high level of literacy/regular use of reading or writing in Turkish).

The model showed a significant effect of only literacy level $(\mathrm{F}(3,596)=6.119 ; p<.001)$; all other main effects and interactions were not significant (all $p \mathrm{~s}>.1$ ). Literacy level had a positive influence on passive production, such that a higher the level of L1 literacy correlated with greater numbers of produced passives as compared to the HSs with no literacy. Those with a low level of literacy were about 6 times more likely to produce passives than those with no literacy $(p=.006$; odds ratio $=5.92)$, those with a medium level of literacy were about 8 times more likely $(p=.042$; odds ratio $=7.95)$, and those with a high level of literacy were over 16 times more likely $(p<.001$; odds ratio $=16.12$ ). An equivalent analysis run with the HS responses on the German test yielded no significant main effects or interactions (all $p \mathrm{~s}>.668$ ), suggesting that the effect of literacy (in Turkish) is only relevant to production in Turkish. A visual representation of individual passive production by literacy level in Turkish for the heritage speakers is given below in Figure 4 (for HS Turkish) and Figure 5 (for HS German).

[Figure 4 near here]

[Figure 5 near here] 


\section{Discussion}

We start the discussion of the data with an important reminder. We did not make any a priori assumptions regarding the competence of the HSs or how HSs might distribute the use of passives in either language, especially for German simply because it is their dominant language. The data presented in the previous section revealed that there are no differences between the HS group and the German native controls. Although this means that there is nothing particularly interesting to further highlight about the HS vs. German-control comparison, having tested both languages of the HSs serves a significant purpose. It is precisely because we tested both languages that we do not need to presume anything regarding the HSs' knowledge of passives in their dominant language, German. In the vast majority of HS studies, only the HL is tested (see Montrul 2008, 2016). Often, differences between HSs and controls are claimed to result from crosslinguistic influence and/or dominant language transfer, and we deduce -without seeking for empirical support- that the majority language is not affected in the same domain. In the present study, we have confirmed how our HSs perform in both languages. This justified more adequately the discussion of the potential effects that knowledge of and dominance in German might have had on the minority language performance.

We now return to the three research questions that guided our project, repeated immediately below for convenience. Beyond addressing these specific questions, we consider how answering them relates to larger debates in the field. The research questions were as follows:

i. Do Turkish HSs in Germany have, at this (young) age of testing, the morphosyntax of passives in both of their languages?

ii. If they can correctly produce the morphosyntactic structure of passives in both languages, does their use of passives differ from that of age-matched native controls in one or both of the languages? 
iii. If there are differences between the HSs and controls and/or simply between individuals in the HS group, how and why might such differences obtain?

\subsection{The morphosyntax of passives in Turkish HSs in Germany}

As regards the first research question, the results of our study confirm that HSs of Turkish tested in Germany—at the elusive, yet crucial age range of 10-15 years-have the underlying representations for passives in both Turkish and German. Although the rate of using passives in Turkish is different for the HS group (and for most but crucially not all HS individuals), every HS produced passives, with an average of 7.45 uses for the aggregate. Recall that whenever a passive was produced, by a control or a HS, it was completely grammatical. For a Turkish passive production to be grammatical (see example $10(\mathrm{~b})$ ), the obligatory grammatical morpheme for passive would need to be produced and the object of an active sentence that has been promoted to the syntactic subject in the passive would need to lose its accusative case marker. Since the by-phrase of the passive $\left(\mathrm{O}_{\mathrm{OBL}}\right)$ is optional, the fact that SV sentences are produced by HSs where the patient depicted is clearly the syntactic subject might not constitute unassailable evidence that they have the morphosyntax of passives because $\mathrm{S}(\mathrm{O}) \mathrm{V}$ is the canonical word order. However, the fact that HSs only produce passive morphology (sometimes with the $\left(\mathrm{O}_{\mathrm{OBL}}\right)$ making it completely clear), specifically when maintaining the patient as the syntactic subject of a response to a patient-focused question, suggests that they have a complete representation of the morphosyntax of Turkish passives. In the responses without passive production there are two patterns: Either the patient-focused question is disregarded and the answer provides the patient in the canonical object position (and, if so, case-marked appropriately), or the patient is kept as the subject but the verb is changed to an appropriate one given the context of the picture that avoids a passive (see the examples in 10 above). Furthermore, when HSs produced passives, morphological case assignment was always correct (lack of obligatory case marking on the sentential subject). We have strong evidence that these Turkish HSs mark accusative case because in 
the remainder of the sentences $(75 \%$ of them) in which they did not produce passives, all accusative (patient) objects were properly case-marked in active sentences. And so, the fact that the syntactic subjects in the passive sentences are properly case-marked (with zero-derivation as required for nominative in Turkish) further indicates they have complete passive representations.

As it relates to passives in German, the data are less controversial overall as they revealed no differences between the controls' and the HSs' production. Not only do the HSs produce the passive in German in a fully grammatical way, they also do so to the same proportion as the controls. Recall that German too has overt case marking, perhaps less transparently than Turkish. And so, in stating that the production of passives was always grammatical entails much more than movement in the sentential word order. This means that all instances of passives produced in German, by HSs or native controls, reflected both correct word order and morphological Case assignment. The HSs' performance in German is not surprising since German is their dominant language as well as the language in which they have been formally educated. It is interesting to observe that passives in German were not ubiquitously used as answers to patient-focused probing questions by either group. Because some passives were produced (roughly $25 \%$ of the time on average), we are confident the experimental design fulfilled its purpose of creating a suitable environment to elicit passives. The fact that passives were produced relatively infrequently, although each patient-theme-focused question set up a natural environment for the production of passives, might just reflect use of passives in authentic German more generally. To our knowledge, there are no studies looking at passives in older children or adults nor are there any corpus studies on the frequency of passive production, but we do know from empirical work that they are rare in early child speech (Abbot-Smith and Behrens 2006; Slobin 1994).

To understand the full significance of the performance of HSs and to justify our conclusion that they have complete passive representations in both of their languages, it is important to underscore one final time the nature of the methodology itself. Recall that this is not a priming study. 
That is, during the course of the experiment the passive was never used by the investigator. As a result, to the extent that the passive was produced, it was organic, coming from the participant's mental grammar. Under the generally accepted truism that one can only spontaneously generate grammatical structures that one has competence of-especially when a specific dedicated morpheme must be employed as is the case for passives in Turkish-, it must be true that all participants know the structure of passives. The fact that HSs know passives in both of their languages, however, does not entail that the trend of their use overall will be similar across HS individuals or in comparison to the control aggregate. This leads us, then, to our second research question; that is, does a HS having competence of particular structure in the HL mean that this structure will be used in a monolinguallike manner?

\subsection{Differences from the age-matched native controls}

Despite having passives represented in both German and Turkish, HSs differ significantly from one of the control groups related to the suppliance of passives in this experimental paradigm. The data reveal that the frequency of passive suppliance significantly differs between the HSs and the controls only in Turkish. First, we must note that the Turkish native controls produced many more instances of passives than the HSs, on average $19 / 28$ as opposed to $7.45 / 28$. Although passives are likely universally rare, passives in Turkish seem to be more frequent and, therefore, potentially more easily elicited in a production measure of this type. To our knowledge, there is no directly comparable corpus analysis that can be used to support a claim that Turkish uses more passives than German. However, work on child language production shows that Turkish children produce more passives than German children (Slobin 1994) through the age of testing (up to age 9). In a crosslinguistic developmental study of Frog Story narratives (Mayer 1969) by child and adult speakers of English, Spanish, German and Turkish, Slobin (1994: 356) reports that German children use a more activesentence oriented narrative strategy and less "syntactic packaging" in linking events as compared to 
the speakers of Turkish. Whatever the reason turns out to be why the Turkish natives produce more passives than German natives under the same methodology, the fact remains that in our study the production of passives is not marginally greater but indeed, on average, over $100 \%$ more. The trend seen for the groups is reflected, more or less, in individual performances. In other words, differences between German and Turkish production of passives under the current methodology seem to be systematic, as confirmed by the statistics. To conclude, although the HSs do not differing in competence from either native control group, they differ significantly from the Turkish controls in suppliance.

\subsection{How and why do differences obtain?}

The heritage speakers' rate of passive suppliance between German and Turkish does not differ significantly. In other words, although they produce passives in both languages they are equally unlikely, again in both languages, to produce a passive over an alternative grammatical structure. Since this conservative approach to producing passives only reflects the German target, it seems reasonable to claim that the dominant language, German, exercises CLI in this domain at the level of production. This CLI is quantitative rather than qualitative because HSs' adopt the same languagespecific rules as monolinguals, but they do it to different extents. The results mirror those form a study of older Turkish HSs in Germany, showing that these speakers were equally sensitive to definiteness effects as monolinguals in both languages, while showing quantitative differences in Turkish (Kupisch et al. forthcoming).

Recall from the results section that the HS aggregate average of passive responses in Turkish did not reflect the individual performances of all individual speakers in the HS group. Indeed, some HSs produced less than the average, several produced well above the average, whereby some (13 out of $22 \mathrm{HSs}$ ) produced a number within the native control range ( $\min =7, \max =28)$. Follow-up correlational statistical tests were run to see if one particular variable or some interaction of variables 
might predict increasingly more target-like suppliance of passives by individual HSs. Indeed, such a model fit was found whereby increased exposure to literacy and only this variable (e.g., having had formal training in the Turkish language through Sunday schools and being able to read and write in Turkish) strongly correlated with increased target-like production of passives. Interestingly, this same regression was run to see if greater literacy in Turkish correlated with more suppliance of passives overall, that is, whether it would predict increased suppliance in Turkish and German or just in Turkish (at an individual level). The statistical analysis revealed that higher Turkish literacy was strictly limited to Turkish production only. Further support for a role for mother-tongue literacy affecting the domain of passives in HSs might come from Putnam and Salmons (2013) who showed that speakers of a moribund variety of heritage German had effectively lost the traditional distinction between stative and eventive passives that select, and instead used an alternative form, an impersonal construction as a way of supressing an agent. Interestingly, none of these HSs were educated in German at all, thus also showing, albeit indirectly, that when HSs have no formal education in the heritage language passives are a vulnerable domain.

\section{Conclusions}

Related to the above, we would like to offer a few comments. First, our data directly support claims made in the literature for over a decade that have, to date, not been sufficiently evidenced empirically. Sorace (2004) and Rothman (2007) independently suggested that some HS differences might be most accurately explained by them not having access to education in the standard variety and thus literacy in the HL. However, tangible evidence to support such a suggestion was extremely limited at the time. Recently, Kupisch and Rothman (2016) reviewed a series of studies showing that HSs under "special" contexts—where "special" refers to HSs who received all of their primary education in the HL, wind up behaving like monolinguals. They review work comparing French and Italian HSs who have lived all their lives in Germany across comparable experiments and unique domains of grammar. 
The French HSs have attended a French school in Germany, where the language of education is mainly French. The Italian HSs have not attended an equivalent school for Italian. Both sets of Romance-German HSs wind up being very competent speakers of both languages, but only the French HSs had a school curriculum comparable to that of monolingual French speakers. Only the Italian HSs wound up behaving differently from monolingual norms. The French HSs were completely monolingual-like, except that some of them had a perceivable foreign accent when speaking German. With such evidence in hand, Kupisch and Rothman (2016) claim that some differences between truly comparable HSs and monolinguals can be reduced to differences in education in the HL.

Our data from the Turkish group seems to point in this same direction. The data show that even when both sets of speakers have shared mental representations, literacy differences can affect how properties of the mental grammar can distribute distinctly in production. Given the entirety of our data, we cannot conclude that having some literacy in the mother tongue in HS situations nullifies all potential differences between HSs and monolinguals. How could it? After all, one group would still be monolingual and the other bilingual. The correlation in our data is very clear; increasing literacy in Turkish equates to increasingly more target-like production. Thus, the effect German has on Turkish cannot be representational at the level of syntactic competence itself, but can be argued to affect the employment of this structure in real time production. What increased literacy seems to convey here, then, is some protection against CLI at the level of language use.

Our data relate nicely to what is now a large body of evidence, suggesting that mother-tongue literacy plays an important role in overall language development and maintenance as well as academic achievement more globally (Baker 2006; Biber and Hared 1991; Bigelow and Tarone 2004; Eisenchlas, Schalley and Guillemin 2013; Hoff 2006; Tsimpli 2014). Studies investigating bilingual communities in Canada, the United States and Australia show that individuals that are not supported by formal literacy training of some type in the HL in the early years of development face problems maintaining their HL over time (see Cummins 2005; Eisenchlas et al. 2013 for review). Maintenance 
of the HL does not only entail preserving the mental grammar against attrition, but also conserving the ways in which the language is used independent from influences of an increasingly dominant other language over time. Accordingly, we tested HSs at the age range of 10-16 to see if indeed increasing age correlated with less target-like competence or use in the HL. As we saw in the results section, age was not a predictive factor alone nor in combination with any secondary factor. The only predictive variable was literacy, irrespective of age.

A second argument that is supported by our data is the increasingly popular view that differences between HSs and monolinguals should not be viewed under a deficit approach (e.g., Aalberse and Hulk 2016; Kupisch and Rothman 2016; Nagy 2015; Pascual y Cabo and Rothman 2012; Putnam and Sánchez 2013). As Grosjean (1989) first coined, bilinguals are "not two monolinguals in one person." And so, showing differences between monolinguals and any set of native bilinguals, e.g. HSs, in the language that the groups share as a/the native language should not be newsworthy, but actually expected. Equally, it should not be surprising that native monolinguals and native bilinguals share similar mental grammars when and only when they have had comparable experiences for this to obtain. It should also not be controversial to say that mental grammars in monolinguals and bilinguals_-and the management of more than one if applicable — are supported by the same finite mental resources. How the two groups represent language and use the representations in production is predicted to be different, as a by-product of the potentially vast differences that distinguish individuals on both the HS and monolingual continua. In the present case, the variables were such that monolinguals and the HSs had enough input and experience with both German and Turkish to acquire passives. However, experience with Turkish was clearly not sufficient for the HSs to use the structure like monolinguals do, unless of course they had extra experience with Turkish that filled the apparent gap. Had we used the criteria of absolute equivalency in use as the determinant to decide whether or not HS grammars are qualitatively similar to monolinguals, then we would have concluded that the HS grammar is deficient for Turkish. However, appreciating that 
producing the passive must mean HSs have competence of it and that less experience with standard Turkish via literacy equates to more German influence allows us to conclude that while HSs are different from monolinguals in production, their grammars are not deficient in any way.

\section{References}

Aalberse, S., and A. Hulk. 2016. "Introduction to the special issue-Heritage language studies and early child bilingualism research: Understanding the connection." International Journal of Bilingualism, doi:10.1177/1367006916654351

Abbot-Smith, K., and H. Behrens. 2006. "How known Constructions influence the Acquisition of other constructions: The German Passive and Future Constructions.” Cognitive Science 30, 9951026.

Aksu-Koç, A., and D. Slobin. 1985. “The acquisition of Turkish.” In The Crosslinguistic Study of Language Acquisition, edited by D. Slobin, volume 1, 839-876. Hillsdale, NJ: Lawrence Erlbaum.

Alcock, K., K. Rimba, and C. Newton. 2013. "Early production of the passive in two Eastern Bantu languages." First Language 32 (4): 459-478.

Alemán Bañón, J., and J. Rothman. 2016. "The role of morphological markedness in the processing of number and gender agreement in Spanish: an event-related potential investigation.” Language, Cognition and Neuroscience 31 (10): 1273-1298.

Alemán Bañón, J., D. Miller, and J. Rothman. (in press). "Morphological Variability in Second Language Learners: An Examination of Electrophysiological and Production Data." Journal of Experimental Psychology: Learning, Memory and Cognition.

Aschermann, E, I. Gülzow, and D. Wendt. 2004. "Differences in the Comprehension of Passive Voice in English-speaking and German-speaking children”. Swiss Journal of Psychology 63 (4), 235245. 
Babyonyshev, M., and D. Brun. 2003. "The role of aspect in the acquisition of passive constructions in Russian." GALA. Utrecht, The Netherlands.

Baker, C. 2006. Foundations of bilingual education and bilingualism. Clevedon, UK: Multilingual Matters.

Barton, D. 2015. “Generische Nominalphrasen bei deutsch-französischer Zweisprachigkeit.” PhD Dissertation, University of Hamburg.

Bates, E., C. Harris, V. Marchman, B. Wulfeck, and M. Kritchevsky. 1995. "Production of complex syntax in normal ageing and Alzheimer's disease." Language and Cognitive Processes 10 (5): 487 539.

Benmamoun, E., S. Montrul, and M. Polinsky. 2013. "Heritage languages and their speakers: Opportunities and challenges for linguistics.” Theoretical Linguistics 39 (3-4): 129-181.

Biber, D., and M. Hared. 1991. "Literacy in Somali: Linguistic consequences." Annual Review of Applied Linguistics 12: 260-282.

Bigelow, M., and E. Tarone. 2004. "The role of literacy level in second language acquisition: Doesn't who we study determine what we know?” TESOL quarterly 38 (4), 689-700.

Bock, J. 1986. "Syntactic persistence in language production.” Cognitive Psychology 18: 355-387.

Borer, H., and K. Wexler. 1987. "The maturation of syntax.” In Parameter Setting, edited by T. Roeper and E. Williams, 123-172. Springer Netherlands.

Brooks, P., and M. Tomasello. 1999. "Young children learn to produce passives with nonce verbs." Developmental Psychology 35 (5): 29-44.

Chang, H. W. 1986. "Young children's comprehension of the Chinese passives." In Linguistics, psychology, and the Chinese language, edited by H. Gao and R. Hoosain, 115-23. Hong Kong: Center of Asian Studies, University of Hong Kong. 
Cummins, J. 2005. “A proposal for action: Strategies for recognizing heritage-language competence as a learning resource within the mainstream classroom." The Modern Language Journal 89: 585592.

De Houwer, A. 1995. “Bilingual language acquisition.” In The Handbook of Child Language, edited by P. Fletcher and B., 219-250. MacWhinney, Oxford: Blackwell.

Demuth, K., and M. Kline. 2006. "The distribution of passives in Spoken Sesotho." Southern African Linguistics and Applied Language Studies 24 (3): 377-388

Eisenchlas, S. A., A. C. Schalley, and D. Guillemin. 2013. "The importance of literacy in the home language: the view from Australia." Sage Open 3 (4), doi:2158244013507270.

Ferreira, F. 2003. "The misinterpretation of noncanonical sentences". Cognitive Psychology 47: 164203.

Ferreira, F., and J. Bock. 2006. "The functions of structural priming". Language and Cognitive Processes 21: 1011-1029.

Fox, D., Y. Grodzinsky, \& S. Crain. 1995. “An experimental study of children's passive”. MIT working papers in linguistics 26: 249-264

Fox, D., and Y. Grodzinsky. 1998. "Children's passive: a view from the by-phrase.” Linguistic Inquiry 29 (2): 311-32

Gabriel, R. 2001 “A Aquisição das Construções Passivas em Português e Inglês: Um Estudo Translingüístico.” PhD dissertation, PUCRS.

Gass, S., and A. Mackey. 2000. Stimulated recall methodology in second language research. Routledge.

Gass, S., and A. Mackey. 2007. Data elicitation for second and foreign language research. Psychology Press. 
Gavarró, A., and X. Parramon, X. 2011. "The acquisition of Catalan passives and the adjectival interpretation.” Paper presented at Linguistic Symposium on Romance Languages, University of Ottawa.

Grosjean, F. 1989. "Neurolinguists, beware! The bilingual is not two monolinguals in one person." Brain and language 36 (1): 3-15.

Haznedar, B. 2013. “Child second language acquisition from a generative perspective.” Linguistic Approaches to Bilingualism 3 (1): 26-47.

Hoff, E. 2006. "How social contexts support and shape language development." Developmental Review 26 (1): 55-88.

Hopp, H. 2013. “Grammatical gender in adult L2 acquisition: Relations between lexical and syntactic variability." Second Language Research 29 (1): 33-56.

Irizarri van Suchtelen, P.2016). "Spanish as a heritage language in the Netherlands. A cognitive linguistic exploration.” PhD dissertation, Utrecht: LOT.

Ketrez, F. N. 1999. "Early verbs and the acquisition of Turkish argument structure." PhD diss., Boğaziçi University.

Kupisch, T. 2013. “A new term for a better distinction?” Theoretical Linguistics 39 (3-4): 203-214.

Kupisch, T., and J. Rothman. 2016. "Terminology matters! Why difference is not incompleteness and how early child bilinguals are heritage speakers." International Journal of Bilingualism. ISSN 1756-6878 doi: 10.1177/1367006916654355

Kupisch, T., D. Akpınar, and A Stöhr. 2013. "Gender assignment and gender agreement in adult bilingual and second language speakers of French." Linguistic Approaches to Bilingualism 3(2): 150-179.

Kupisch, T., T. Lein, D. Barton, D.J. Schröder, I. Stangen, and A Stoehr. 2014. “Acquisition outcomes across domains in adult simultaneous bilinguals with French as weaker and stronger language.” Journal of French Language Studies 24(3): 1-30. 
Kupisch, T., A. Belikova, Ö, Özçcelik, I. Stangen, and L. White. forthcoming. "Restrictions on definiteness in the grammars of German-Turkish heritage speakers. Linguistic Approaches to Bilingualism". doi: 10.1075/lab.13031.kup

Leech, R., J. Aydelott, G. Symons, J. Carnevale, and F. Dick. 2007. "The development of sentence interpretation: Effects of perceptual, attentional and semantic interference." Developmental science 10(6): 794-813.

Mayer, M. 1969. Frog, where are you?. New York: Dial Press

Meisel, J. M. 2004. “The Bilingual Child.” In The Handbook of Bilingualism., edited by T. K. Bhatia \& W. C. Ritchie, 91-112. Oxford: Blackwell.

Meisel, J.M. 2011. First and Second Language Acquisition: Parallels and Differences. Cambridge: CUP.

Messenger, K., H.P. Branigan, J.F. McLean, and A. Sorace. 2012. “Is young children’s passive syntax semantically constrained? Evidence from syntactic priming." Journal of Memory and Language 66 (4): 568-587.

Mills, A. E. 1985. "The acquisition of German." In The Crosslinguistic Study of Language Acquisition, edited by D. Slobin, volume 1, 141-254. Hillsdale, NJ: Lawrence Erlbaum.

Montrul, S. 2008. Incomplete acquisition in bilingualism. Re-examining the age factor. Amsterdam: John Benjamins

Montrul, S. 2016. The Acquisition of Heritage Languages. Cambridge University Press.

Montrul, S., and N. Sánchez-Walker. 2013. "Differential object marking in child and adult Spanish heritage speakers." Language Acquisition 20 (2): 109-132.

Nagy, N. 2015. “A sociolinguistic view of null subjects and VOT in Toronto heritage languages”. Lingua, 164, 309-327. 
Özsoy, S. 2009. “Argument Structure, Animacy, Syntax and Semantics of Passivization in Turkish: A corpus-based approach" In Corpus Analysis and Variation in Linguistics, edited by Y. Kawaguchi, M. Minegishi and J. Durand, 259-279. Amsterdam: John Benjamins.

Pascual y Cabo, D. 2013. "Knowledge of gustar-like verbs in Spanish heritage speakers". In. Proceedings of the 12th GASLA Conference Somerville, edited by J. C. Amaro, T. Judy, and D. Pascual y Cabo, 162-169. MA: Cascadilla Proceedings Project.

Pascual y Cabo, D., and J. Rothman. 2012. “The (Il)logical problem of heritage speaker bilingualism and incomplete acquisition". Applied Linguistics 33 (4): 50-455.

Pickering, M.J. and V.S. Ferreira. 2008. "Structural priming: A critical review". Psychological Bulletin, 134: 427-459.

Pierce, A. 1992. “The Acquisition of Passives in Spanish and the Question of A-Chain Maturation”. Language Acquisition 2 (1): 55-81.

Pires, A., and J. Rothman. 2009. “Disentangling sources of incomplete acquisition: An explanation for competence divergence across heritage grammars". International Journal of Bilingualism, 13 (2): 211-238.

Polinsky, M. 2011. "Reanalysis in adult heritage language: A case for attrition". Studies in Second Language Acquisition 33: 305-328

Putnam, M. T., and J. C. Salmons. 2013. "Losing their (passive) voice: Syntactic neutralization in heritage German". Linguistic Approaches to Bilingualism, 3(2): 233-252.

Putnam, M. T., and L. Sánchez. 2013. "What's so incomplete about incomplete acquisition?: A prolegomenon to modeling heritage language grammars". Linguistic Approaches to Bilingualism 3 (4): $478-508$.

Rothman, J. 2007. "Heritage speaker competence differences, language change and input type: Inflected infinitives in heritage Brazilian Portuguese". International Journal of Bilingualism 11: 359-389. 
Rothman, J. 2009. "Understanding the nature and outcomes of early bilingualism: Romance languages as heritage languages”. International Journal of Bilingualism, 13 (2): 155-163.

Rowland, C. F., Chang, B. Ambridge, Pine, J. M., and E. V. Lieven. 2012. "The development of abstract syntax: Evidence from structural priming and the lexical boost". Cognition 125 (1): 49 63.

Savaşır, I., and J. Gee. 1982. "The functional equivalents of the middle voice in child language," Annual Meeting of the Berkeley Linguistics Society 8: 607-616.

Scontras, G., Z. Fuchs, and M. Polinsky. 2015. "Heritage language and linguistic theory," Frontiers in Psychology 6: 7-26.

Serratrice, L. 2013. "Cross-linguistic influence in bilingual development: Determinants and mechanisms," Linguistic Approaches to Bilingualism 3 (1): 3-25.

Slobin, D. 1985. "Why study language crosslinguistically?” In The crosslinguistic study of language acquisition, edited by D. Slobin, 3-24. Hillsdale, NJ: Lawrence Erlbaum Associates

Slobin, D. 1994. “Passives and alternatives in children's narratives in English, Spanish, German, and Turkish". In Voice: Form and Function, edited by B. Fox, P. Hopper, 341-364. Amsterdam: John Benjamins.

Sorace, A. 2004. "Native language attrition and developmental instability at the syntax-discourse interface: Data, interpretations and methods," Bilingualism: Language and Cognition 7: 143-145.

Sugisaki, K. 1999. “Japanese passives in acquisition". UCONN Working Papers in Linguistics 10: $145-56$.

Terzi, A. and K. Wexler. 2002. “A-chains and S-homophones in children’s grammar: Evidence from Greek passives". In Proceedings of the Northeast Linguistic Society (NELS) 32, edited by M. Hirotani, 519-537. South College, MA: GLSA (Graduate Linguistic Student Association).

Tomasello, M. 2000. “Do young children have adult syntactic competence?” Cognition 74: 209-253. 
Tomlin, R. S. 1995. "Focal Attention, Voice, and Word Order: An Experimental Cross-Linguistic Study," In Word Order in Discourse, edited by P. Downing and M. Noonan, 517-554. Amsterdam and Philadelphia: John Benjamins.

Tomlin, R. 1997. "Mapping Conceptual Representations into Linguistic Representations: The Role of Attention in Grammar," in Language and Conceptualization, edited by J. Nyuts, and E. Pederson, 162-189. Cambridge: Cambridge University Press.

Topbaş, S., I. Mavis, and M. Basal. 1997. "Acquisition of bound morphemes: nominal case morphology in Turkish". In Proceedings of the VIIIth International Conference on Turkish Linguistics, edited by K. Imer, and N. Uzun, 22-36. Ankara: Ankara Üniversitesi Basimevi.

Tsimpli, I. M. 2014. "Early, late or very late?: Timing acquisition and bilingualism," Linguistic Approaches to Bilingualism 4 (3): 283-313.

Van der Heijden, H. 1999. "Word formation processes in young bilingual children". In Studies on Language Acquisition, edited by G. Extra and L. Verhoeven, 123-140. Volume 14: Bilingualism and Migration Berlin: Mouton de Gruyter.

White, L., E. Valenzuela, M. Kozlowska-Macgregor, and Y. Leung. 2004. "Gender and number agreement in nonnative Spanish", Applied Psycholinguistics 25 (1): 105-133.

Xanthos, A., S. Laaha, S. Gillis, U. Stephany, A. Aksu-Koç, A. Christofidou, and W.U. Dressler. 2011. "On the role of morphological richness in the early development of noun and verb inflection," First Language 31(4): 461-479.

Table 1: Participants

\begin{tabular}{|l|c|c|c|}
\hline Groups & Heritage & Monolingual & Monolingual \\
& speakers & Turkish & German \\
\hline
\end{tabular}




\begin{tabular}{|l|l|c|c|c|}
\hline \multicolumn{2}{|l|}{ Number } & 22 & 20 & 20 \\
\hline \multirow{3}{*}{ age } & min. & 10 & 10 & 9 \\
\cline { 2 - 5 } & max. & 16 & 14 & 15 \\
\cline { 2 - 5 } & Mean & 12.7 & 12.3 & 12.1 \\
\hline \multirow{3}{*}{ gender } & Female & 13 & 13 & 11 \\
\cline { 2 - 5 } & Male & 9 & 7 & 9 \\
\hline
\end{tabular}

Table 2. Descriptive statistics: use of passives across groups

\begin{tabular}{|l|c|c|c|c|}
\hline Language & \multicolumn{2}{|c|}{ Turkish } & \multicolumn{2}{c|}{ German } \\
\hline Groups & HSs & Monoling & HSs & Monoling \\
\hline
\end{tabular}




\begin{tabular}{|l|l|c|c|c|c|}
\hline \multicolumn{2}{|l|}{ Number } & 22 & 20 & 22 & 20 \\
\hline \multirow{2}{*}{ Mean } & value & $7.45 / 28$ & $19.00 / 28$ & $7.18 / 28$ & $7.80 / 28$ \\
\cline { 2 - 6 } & $\%$ & 26.62 & 67.85 & 25.64 & 27.85 \\
\hline Std. Deviation & 4.02 & 4.96 & 5.54 & 3.02 \\
\hline min. & 1 & 7 & 0 & 0 \\
\hline max. & 13 & 28 & 17 & 14 \\
\hline
\end{tabular}

Figure 1. The fish film event 


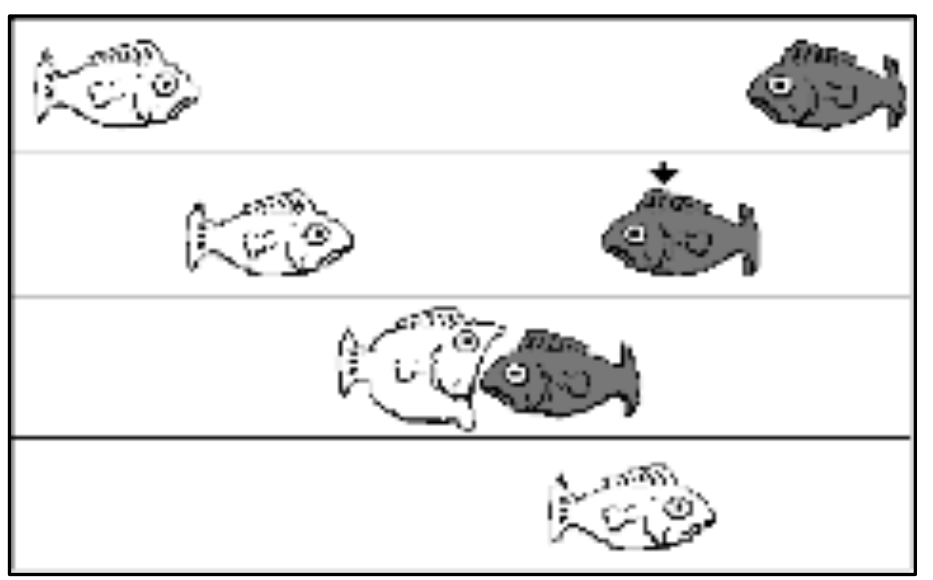

Figure 2. Passive elicitation task pictures 


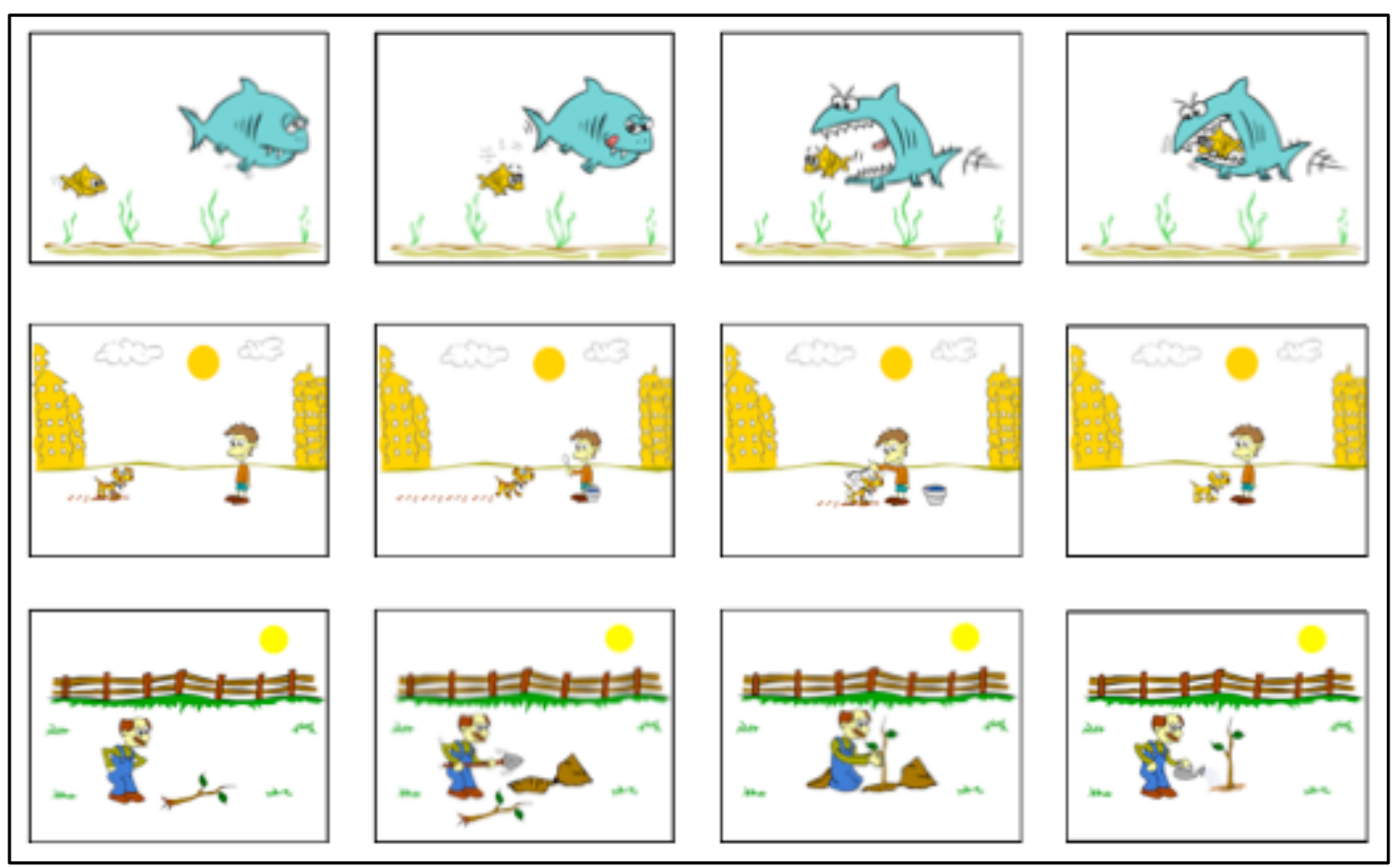


Figure 3. Passive production by group (left column is absolute number of productions, $\max =28$ )

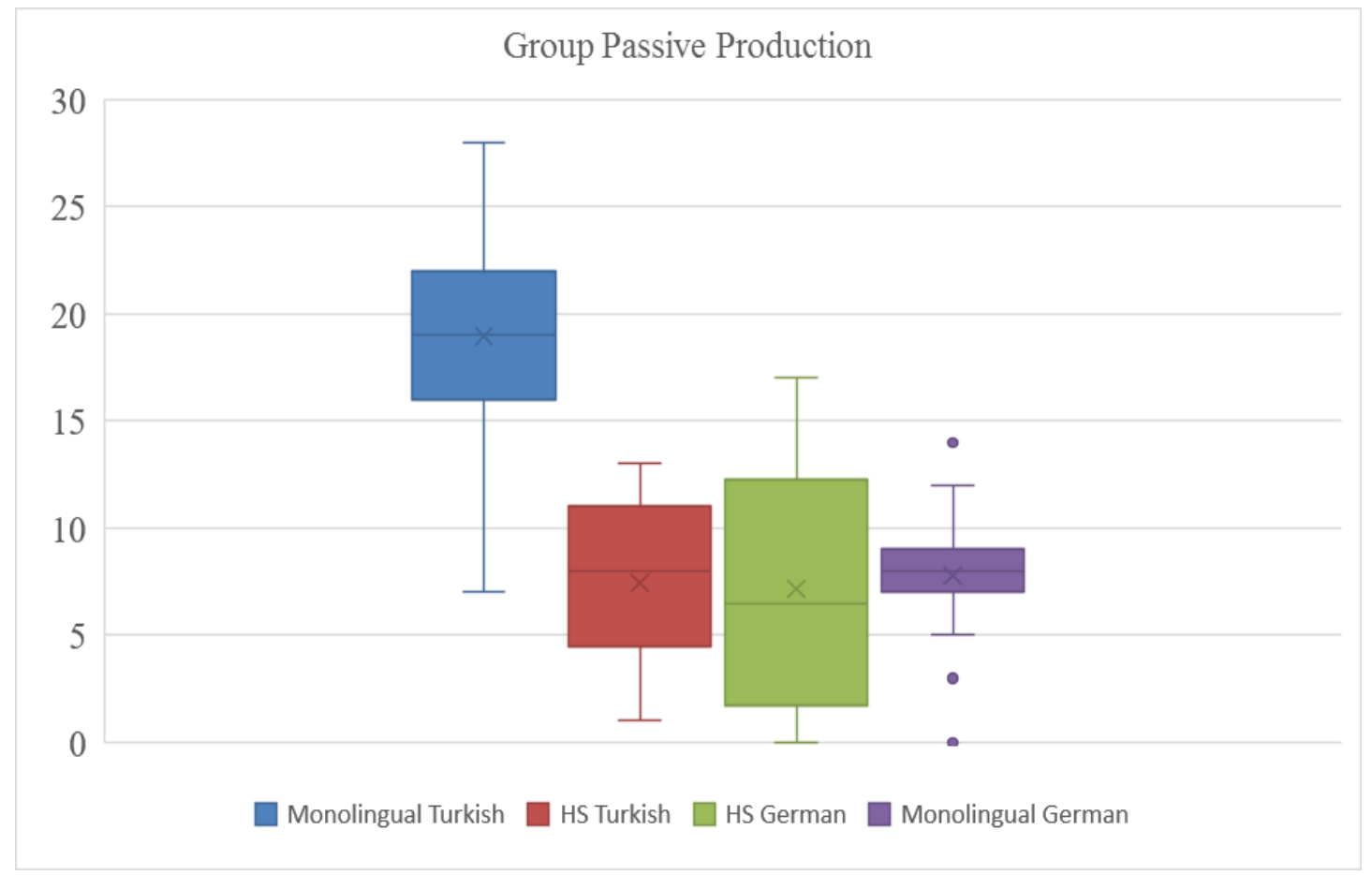


Figure 4. Individual passive production by HSs in Turkish: (left column is absolute number of productions; right column is the corresponding percentage produced or the raw number (n) out of 28, the number of potential productions in the elicitation task).

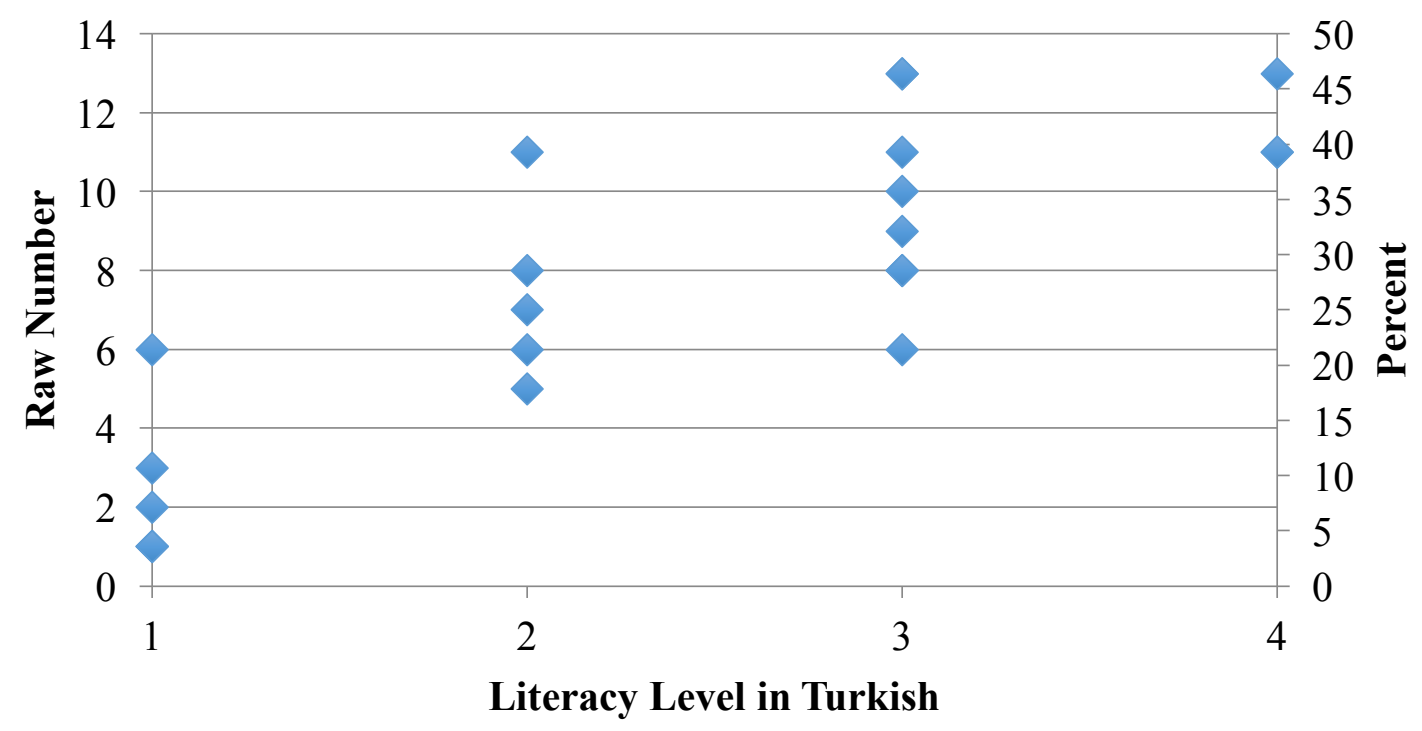


Figure 5. Individual passive production by HSs in German.

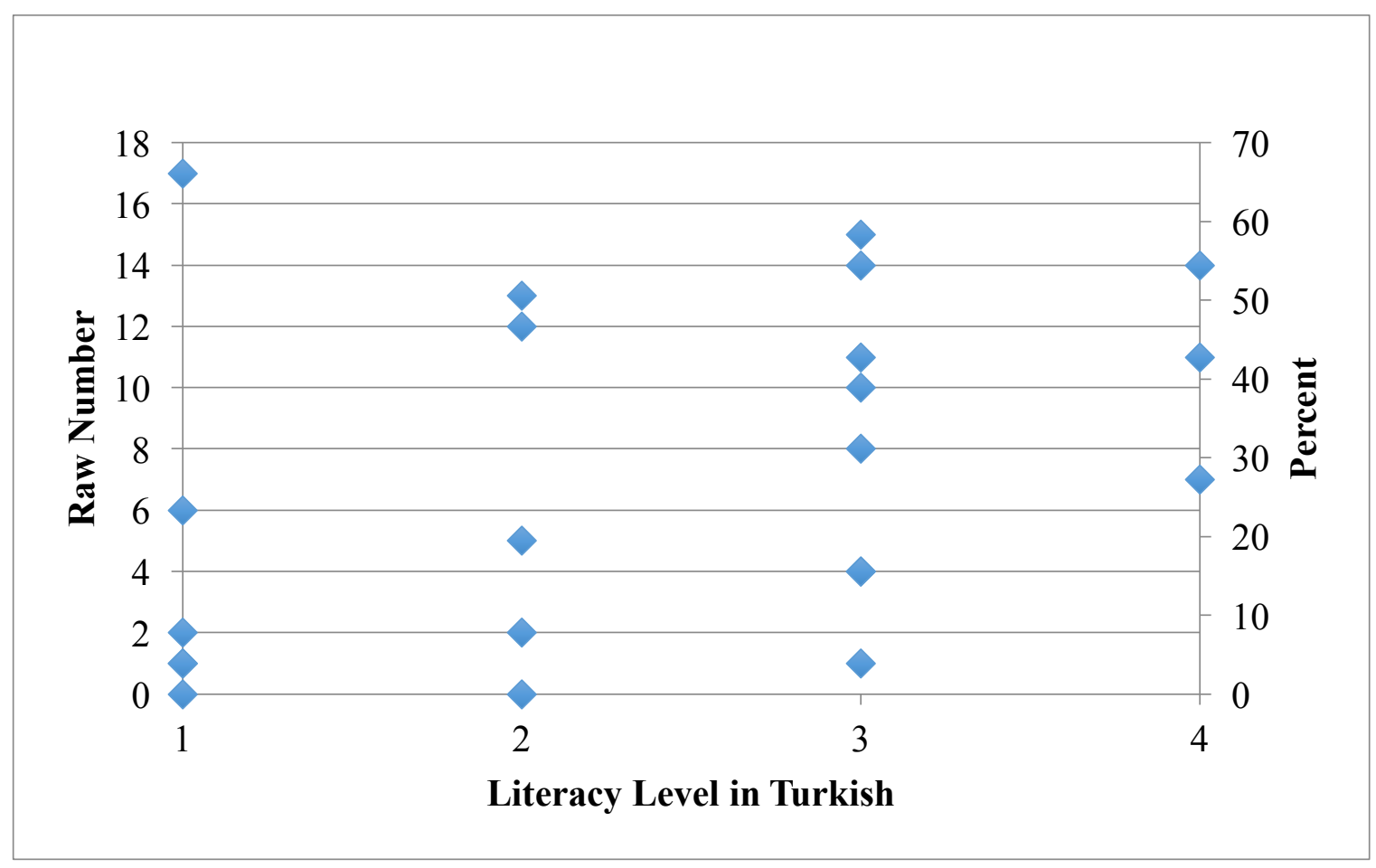

